DOI: 10.24234/wisdom.v15i2.355

Dmitry SEMKIN,

Lyubov BUSHUEVA

\title{
GIACOMO PUCCINI'S OPERATIC LEGACY AND ITS STUDY IN THE PRACTICE OF VOCALISTS
}

\begin{abstract}
The purpose of this article is to analyze the Opera legacy of Giacomo Puccini from the standpoint of practical vocal pedagogy, which, according to the authors, is necessary for the formation of vocal and performing skills of young singers of the academic direction. The authors suggest a historical overview of the main works of the composer in this genre, based on the study of their vocal characteristics, and the author reveals the features of his unique Arioso-recitative style. Various research methods (the aesthetic, vocaltechnical and methodological analyses in particular) reveal that the works by G. Puccini are of particular significance for the development of vocalists' singing breath, musicality, imaginative thinking, mastering of the technique of cantilena, continuous legato (as the basis of bel canto), improving the timbral colours of the voice, its dynamic nuances, developing the right senses of agogics.

The above is confirmed by the analysis of the peculiarities of performance technique and interpretation of one of the composer's most famous works for the tenor voice - Calaf's aria "Nessun dorma" from the opera "Turandot" (which was the main subject of this study).
\end{abstract}

Keywords: vocal art, Opera legacy, Giacomo Puccini.

Introduction

In December 2018, it was the $160^{\text {th }}$ anniversary of the birth of the outstanding world composer, the author of great opera masterpieces, the brilliant melodist Giacomo Antonio Domenico Michele Secondo Maria Puccini (1858-1924). An opera composer in the best sense of the word, Giacomo Puccini brilliantly continued and developed the traditions of Giuseppe Verdi (18131901) in the Italian musical theatre. However, the significance of his activity has an independent value ${ }^{1}$ (Barabanov, 2008; Danilevich, 1969;

See Dzhakomo Puchchini (Giacomo Puccini, in Russian). Retrieved June, 26, 2020 from: https://music.epublish.ru/p317aal.html.
Puccini, 2020). According to researchers of the composer's work, music historians I. V. Nestiev (1966) and L. V. Danilevich (1969), he is rightly considered a representative of verismo in opera, and also researchers observe the influence of impressionism in his works ${ }^{2}$ (Barabanov, 2008; Danilevich, 1969; Puccini, 2020; Gobbi, 1989).

Among the vast heritage of G. Puccini, represented by works of different genres, received the highest recognition for his twelve operas. Puccini himself spoke of a unique passion for this genre: "God touched me with his little finger and said, "Write for the theater and only for the

2 See Dzhakomo Puchchini (Giacomo Puccini, in Russian). Retrieved June, 26, 2020 from: https://music.epublish.ru/p317aa1.html. 
theater" (Puccini, 2020).

Having received his education at the Milan Conservatory, the composer created a one-act Opera "Le Villi" (1883) in order to participate in the competition. A few years later, he wrote the Opera 'Edgar", commissioned by the publisher Giulio Ricordi, which was staged in Milan in 1888. Despite certain fame, these works were still only a specific step to the success that brought him completed in 1893 "Manon Lescaut". It marked the beginning of the long-term work of G. Puccini with regular librettists Luigi Illica and Giuseppe Giacosa.

The subsequent Opera "La Boheme" (1896) made the composer famous throughout the world, and it is still one of the most recurrent repertories. "Tosca", which premiered in 1900, also became a masterpiece. On February 17, 1904, opera "Madame Butterfly" was shown at La Scala, but this performance did not have the success accompanied previous productions. After a significant revision of the work and with a different cast of performers, a new, now triumphant premiere of the same opera took place in May of the same year.

The next work - "La fanciulla del West" was published only in 1910. G. Puccini himself sometimes referred to it as his most powerful creation. The composer also tried to turn to another popular genre of the time - operetta, but without achieving the desired result, he revised it into the Opera "La rondine", staged in 1917.

After reviewing a variety of themes and subjects, including works of Russian literature by Lev Tolstoy and Maxim Gorky, Giacomo Puccini came up with the idea of creating a triptych - a three-part cycle of operas in the style of the Parisian Grand Guignol (horror, sentimental tragedy and farce). It includes the dramatic Opera "Il tabarro", the lyric Opera "Suor Angelica" and the comic Opera "Gianni Schicchi". The last of them, delivered in 1918, received the greatest popularity.

Being terminally ill, Puccini is working on the last monumental Opera-the legend "Turandot" based on the play by C. Gozzi. It was intended to be large-scale and multi-faceted (Plotnikova, 2015), but death prevented its completion. The composition, finished by F. Alfano, was based on existing sketches by G. Puccini, was staged in 1926 at La Scala.

\section{Theoretical Framework}

Even today, the works of the Italian Master, especially "La Boheme", "Tosca" and "Madame Butterfly", are among the most popular in theatres in many countries of the world. Without detracting from the merits of other outstanding composers of the early twentieth century, we note that Giacomo Puccini is undoubtedly one of the most brilliant opera melodists. We can surely talk about the creation of G. Puccini's unique Arioso-recitative style, rich in terms of the possibilities of melodic development that he discovered. Its features are:

- the inseparability of action and music, the composer had almost no overtures (example 1 - Introduction to the Opera "Tosca");

- melodic richness and ingenuity (examples $2,3)$;

- using "Puccini's octaves";

- some other "favourite" stylistic features (for example, when performing vocal parts in the tempo often used by the author - Andante sostenuto, a certain delay in the last beat of bar is typical as in Pinkerton's Arioso from the third act of the Opera "Madame Butterfly" ("Addio, fiorito asil!") or in the famous aria of Calaf from the Opera "Tu- 
randot" (example 2);

- a rich harmonic language in which the resolution of $\mathrm{D}$ (the dominant) in $\mathrm{S}$ (the subdominant) instead of $\mathrm{T}$ (the tonic), parallel fifths and other features can occur (example 1 and example 3). Starting with harmonies in the spirit of late romanticism, the composer gradually brought his style closer to the impressionistic manner, taking from Debussy and Ravel such stylistic features as parallelisms of seventh chords, whole-tone scales, and quart combinations based on the pentatonic scale;

- bright timbral solutions in the spirit of the Impressionists, unusual playing with the orchestral colours, the use of acoustic effects that create the illusion of a multidimensional space.

Besides, the very choice of libretto contributed to the vivid manifestation and development of the psychological component of the characters.

All of the above mentioned explains the absolute value of the composer's opera heritage in vocal performance practice, for the development of the voices of opera singers and the improvement of their vocal and technical potential. This is also facilitated by:

- smoothness and flexibility of beautiful melodies;

- an abundance of tempo deviations even in relatively small fragments of solo numbers (for example, in Cavaradossi's aria "E lucevan le stelle..." from the third act of the Opera "Tosca");

- ease of performing melodic intervals, allowing you to maintain an accurate vocal position and to practice the techniques of portamento to move from lower to higher sounds of the range; all that is an essential component of the Italian singing school.

From the vocal-technical and vocal-performing point of view the works of Puccini are useful for:

- development of singing breathing;

- development of musicality and imaginative thinking;

- mastering the technique of cantilena, long legato as the basis of bel canto;

- improving the timbral qualities of the voice;

- developing a sense of dynamic nuances and contrasts;

- development of correct senses of agogics.

\section{Methodology}

Based on the methodological traditions established in Russian musicology, we can refer to the general principles of Russian vocal pedagogy (Dmitriev, 2000; Morozov, 2008). Nevertheless, in any case, we take into account the basic principles of Italian vocal school (Miller, 2002; Zaitov, 2016). In this article, we use the vocal-technical analysis, as well as vocal-performing analysis of the famous operatic solo fragments. We believe G. Puccini's operas to be very useful for the development of "aesthetic perception", including "psychological mechanisms of influence of performing art, being poly-artistic at its core" (Aryabkina, Spiridonova, Kapranova, Savaderova, \& Mayorova, 2019). On the other hand, these materials could help to develop "the methodical readiness of future music art teachers for their further professional activity" (Ovcharenko, Matveieva, \& Chebotarenko, 2020).

\section{Results and Discussion}

Let us take a closer look at the vocal-technical features of the performance of the most fa- 
mous in the tenor repertoire - Calaf's Aria "Nessun dorma" from the Opera "Turandot" (example 2).

The Aria is written in the key of G-dur, saturated with a rich palette of harmonic colours. The impression of eastern languor, refinement and elegance in the composition largely determines the scale-harmonic features. A long-sustained organ point on the G-dur triad, combined with a colourful chromatized minor seventh chord, creates an impression of static, which is overcome later by an intense melodic development based on consecutive turnovers leading to a powerful culmination. The composer's favourite tempo, Andante sostenuto, suggests the singer have a flexible and extended breath and to perform some delay on the last beat of bar - in this case, on the fourth. The range of the aria supposes the singers to have free mastering of high tessitura (long-lasting high tenor notes "a" and " $h$ ") and contains almost no low notes, that last is typical of the composer's creative handwriting.

After the short one-bar introduction, during which one may inhale through the nose due to the rather slow tempo, there is followed in melody, starting with "d", by an octave movement down. It is recommended not to make a too explicit piano, and when going down, even taking a breath, be sure to maintain a high position of sound retrieving. Next - for the sound " $d$ " (Prin-cipe-ssa) and the sound "b" (fred-da), you should perform a barely noticeable delay, in accordance with the style of the composer. Of course, here and further it is necessary constantly monitor the performance of the "infinitely" flowing melodic line, absolutely smooth "horizontal".

The sounds of "fis" in the next bar (Guardi le stelle) should be softly covered. Crescendo and diminuendo in these two bars must, of course, be emphasized, but gently and unobtrusive- ly. Diminuendo on the phrase "e di speranza" and the accent on the syllable "di", that last in itself does not carry a semantic load, ultimately come from the stylistic intent of the composer. Here this is about Calaf's secret hope for the realization of a cherished dream. Ritenuto at the end of the corresponding bar should be useful to relieve any tension in the vocal apparatus and take a full breath before the first tessiturally difficult part of the aria.

Specifying a tempo before subsequent bars indicates that the performer should return to the original tempo, but not to the original emotion. The variable size, which is often the case with Puccini, in the second bar of this fragment, reflects the development of the emotional image, some agitation. The tenuto signs above the notes "e" and "fis", unfortunately, are not always executed by singers. Here, perhaps, this is justified by the steady progressive movement of music. Notice the ascending melodic moves to be performed as free as possible, without extra load, while maintaining the absolute evenness of the eighth durations.

Professional ability to quickly and accurately take a good breath before the next high-tessitura phrase allows to do it after the words No, no (notes "d" and "e") before the words "sulla tua bocca". Moreover, the corresponding notes have the tenuto signs. Here the vocal apparatus should be absolutely relaxed, free, and the larynx should be without any overloads, larynx position remains unchanged. At the same time the root of the tongue, taken back and down (of course, taking into account the individuality of the performer) should provide the comfortable formation of the cavity over the vocal cords in the larynx before performing the phrase "sulla tua bocca lo diro". Similarly, one needs to perform the phrase "Dilegua, o notte! Tramontate, stelle!" in the se- 
cond high-tessitura part of the aria. For a long enough fermata on "e" (splen-dera), you can take a breath before the corresponding word.

The next phrase ("Ed il mio baccio sciogliera il silenzio, che ti fa mia...") should be sung very warmly and soulfully, as this makes the very important figurative and semantic load, the accent on the note " $b$ " (che ti...) can be, traditionally, supplied by a fermata. In our opinion, the last one is justified in its form and style.

Then the orchestral playing (in the performance the choir sings here) allows the vocalist to "rest" and prepare for the second high-tessitura part of the aria - "Dilegua, o notte! Tramontate, stelle!...". Before this part, one allows a fairly slow and calm inhale (we are not just talking about a deep breathing, but about the so-called low breathing, the mechanism of which ensures the correct performance of works by G. Puccini, G. Verdi and other "powerful" opera composers). Notice that the expressiveness of the delays on the last beats of the measures Puccini twice emphasized by the indication poco rit.

The caesura for taking breath before the words "All' alba vincero..." is mandatory, since we are before the most difficult part of the aria. Long-time fermata on note " $\mathrm{e}$ " is not recommended for those, who are still mastering the aria, just to save energy.

The crescendo molto indicated in the next bar, as well as the increasing sonority of the orchestra, should in no case provoke the singer to over-amplify the sound of "d". This is not an appropriate case. Only the "concentration" of resonator sensations and the use of the resonator capabilities of a specific "singing device" should take place here, without forcing the sound, the last one necessarily prevents the free out to the performance of the upper " $h$ ".

The final three bars of the aria are the most difficult ones for singers. After performing "d", the melody ascends to "g". This is the sound that largely determines the "success" of the coda. As shown by the long-term practice of many great singers (remember, of course, L. Pavarotti), without a full-fledged performance of the so-called covered sound on the " $\mathrm{g}$ ", the work of the voice apparatus here, as in the majority of other examples, will not be built correctly. In our opinion, of course, the Russian term "cover-up" is not very successful, but there are no other suitable commonly accepted terms. Unfortunately, there is no such thing.

Of course, before the final "Vincero" should take a good breath, but here we are faced with a vocal "trick". In contrast to the generally accepted transfer of a sounding consonant (in this case $-\mathbf{n}$ ) to the next syllable (in this case ce), performers "leave" $\mathbf{n}$ with the syllable vin, forming the vowel $\mathbf{e}$ (the sound "h") immediately in the next high sound position after the consonant $\mathbf{c}$. At the same time, the rule of retention of the unchanged position of the larynx (see above - about the root of the tongue) and a wide-open pharynx is unshakeable.

Further, the success of fermata on " $h$ " and the duration of free "a" is determined by the quality of the technology of singing breathing (namely, singing exhalation) and, of course, requires sufficient professionalism.

Of course, the Calaf's Aria, that we have analyzed, should not be performed by junior students of vocal universities, and it may be recommended not to all tenors in senior courses.

Giacomo Puccini's music makes high demands on the performers of the central opera parts. For example, the challenging party of Cio Cio San assumes the female singer has powerful, technically equipped soprano (dramatic, lyric dramatic, lyric powerful), and, at the same time, 
the ability to possess a vast dynamic range of a singing voice - from the delicate pianissimo to dramatic fortissimo. Moreover, one needs the ability timbral convincingly convey the enormous range of feelings and emotions. The stage image of Cio Cio San is also very demanding: the necessary combination of a fragile and delicate appearance with a powerful voice is very rare. It is inexcusably not to mention as other examples: the parties of Rudolph in "La Boheme" and Pinkerton in "Madame Butterfly", which assume exclusively free and "literate" upper sounds from the performing tenor, etc.

\section{Conclusion}

So, we believe that G. Puccini's operas are very useful for the development of musical culture both for listeners and music teachers as a "school of melody".

Opera singer, opera soloist, is a specific profession that requires a whole set of special data and constant complex work on yourself. Therefore, in such a responsible matter as the education of an opera artist, the works of $G$. Puccini could have a significant impact on the students. Puccini demonstrates the unity of word, music and vocal technique in the structure of Opera (Prikhodovskaya, 2010). The activity of vocal directions in music universities, and the Faculty of Arts of the Chuvash State University named after I. N. Ulyanov (Semkin, 2016), in particular, on the effective introduction of the vocal heritage of the world-recognized genius G. Puccini into teaching and performing practice, will undoubtedly contribute to raising the level of vocal-performing culture in the modern musical life of both the Chuvash Republic and Russia.

\section{REFERENCES}

Aryabkina, I., Spiridonova, A., Kapranova, O., Savaderova, A., \& Mayorova, N. (2019). Razvitie kul'turno-esteticheskogo vospriyatiya lichnosti sredstvami ispolnitel'skogo iskusstva (Development of Personal Cultural and Aesthetic Perception by Means of Performing Art, in Russian). Amazonia Investiga, 8(19), 514-520.

Barabanov, N. (2008). Dzhakomo Puchchini (1858-1924) (Giacomo Puccini (18581924), in Russian). Art, 22, 8-18.

Danilevich, L. V. (1969). Dzhakomo Puchchini (Giacomo Puccini, in Russian). Moscow: Music.

Dmitriev, L. B. (2000). Osnovy vokal'noi tekhni$k i$ (Fundamentals of Vocal Technique, in Russian). Moscow: Music.

Gobbi, T. (1989). Mir ital'yanskoi opery (The World of Italian Opera, in Russian). Moscow: Raduga.

Miller, R. (2002). National School of Singing: English, German, and Italian Techniques of Singing Revisited. Scarecrow Press Publ.

Morozov, V. P. (2008). Iskusstvo rezonansnogo peniya. Osnovy rezonansnoi teorii $i$ tekhniki (Art of Resonance Singing. Basis of Resonance Theory and Technique, in Russian). Moscow: Publ. by Institute of Psychology under the Russian Academy of Sciences and Moscow State Conservatoire.

Nestiev, I. V. (1966). Dzhakomo Puchchini: Ocherk zhizni i tvorchestva (Giacomo Puccini: an Essay on Life and Creativity, in Russian). Moscow: Music. 
Ovcharenko, N., Matveieva, O., \& Chebotarenko, O. (2020). Formirovanie metodicheskoi gotovnosti budushchikh uchitelei muzykal'nogo iskusstva $k$ professional'noi deyatel'nosti (Metodological Readiness Formation of Future Music Art Teachers for Their Professional Activity, in Russian). Amazonia Investiga, 9(27), 157-164.

Plotnikova, O. M. (2015). Dialog kul'tur v opere Puchchini "Turandot" (Dialogue of Cultures in the Opera "Turandot" by Puccini, in Russian). Music Scholarship, 1, 19-23.

Prikhodovskaya, Y. A. (2010). Edinstvo slova, muzyki i vokal'noi tekhniki $v$ strukture opery) The Unity of Word, Music and
Vocal Technique in the Structure of Opera, in Russian). Music Scholarship, $1,178-181$.

Semkin, D. N. (2016). Podgotovka vokal'noispolnitel'skikh kadrov v CHuvashskom gosudarstvennom universitete: itogi dvadcatiletiya (Training of Vocal Performing Personnel in the Chuvash State University: Results of the Twentieth Anniversary, in Russian). Bulletin of the Chuvash University. Humanities, 2. 131-138.

Zaitov, G. S. (2016). Osobennosti ispolnitel'skogo iskusstva masterov Shkoly Bel'kanto (Features of the Performing Art of Belcanto School Masters, in Russian). $M u$ sic Scholarship, 1, 107-113.

Appendix:

Example 1.

The first bars of the Opera "Tosca" are a small introduction.

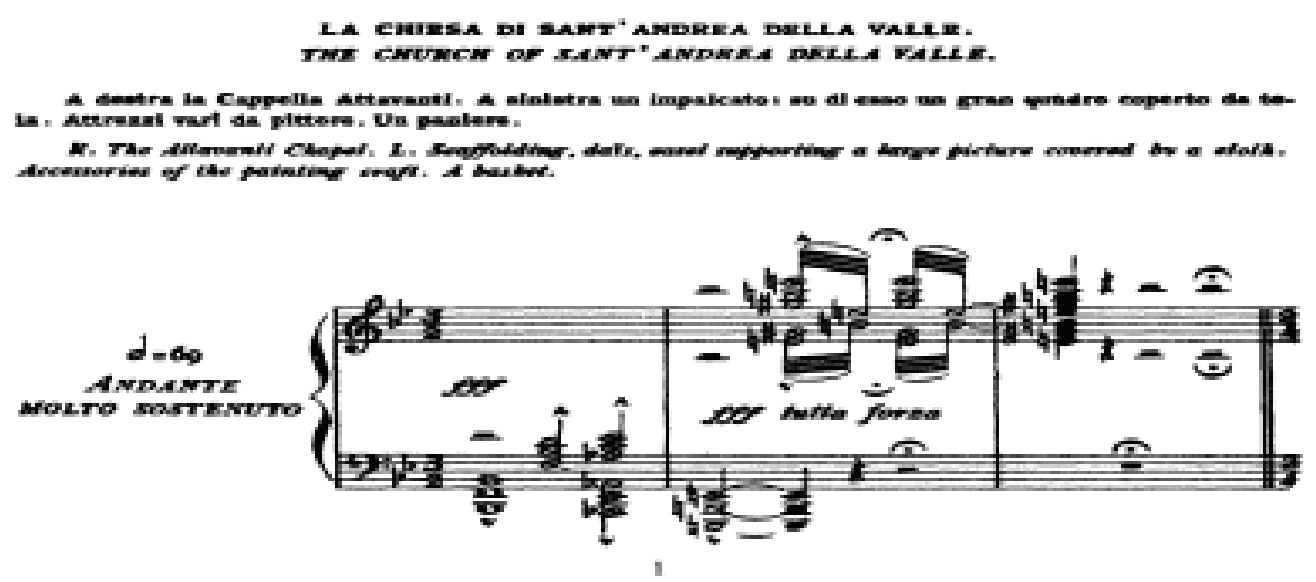



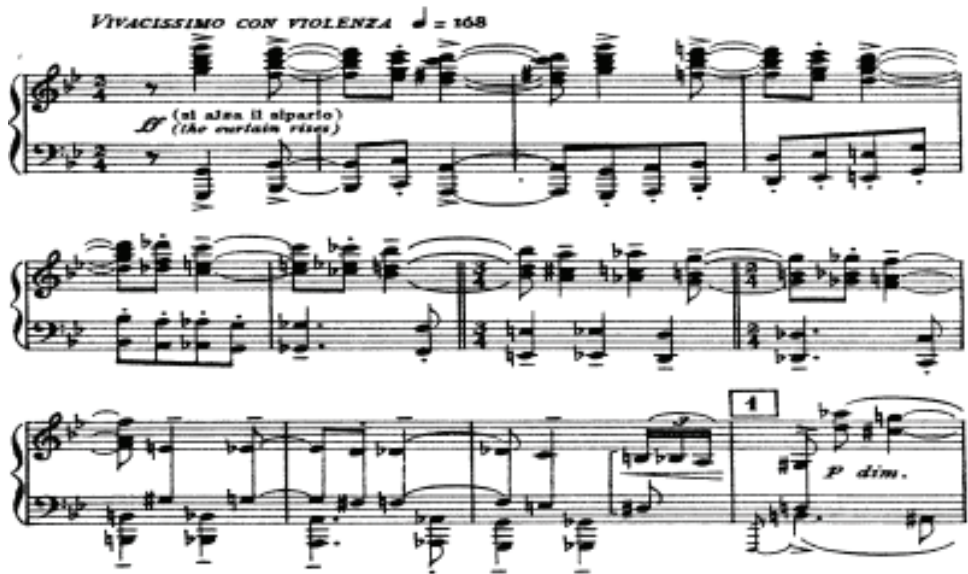

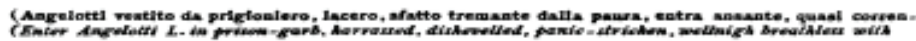
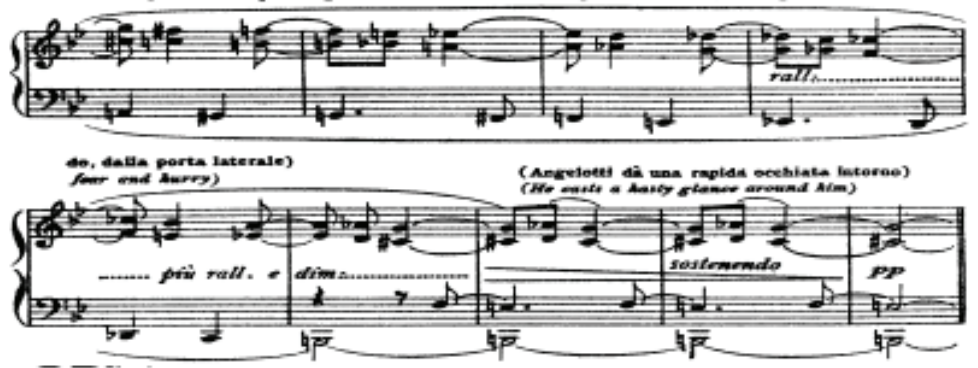

Example 2.

Aria of Calaf from act 3 of the Opera "Turandot".
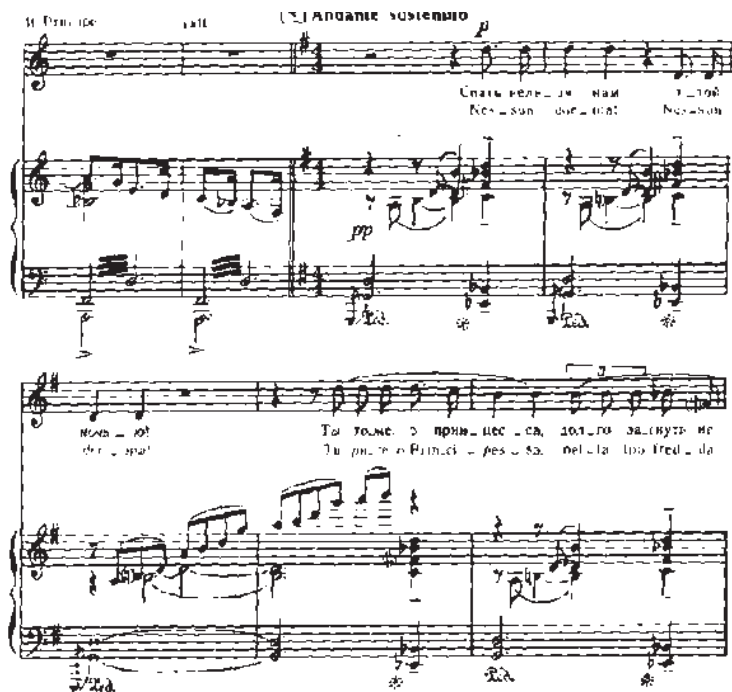

$?_{?+}^{\eta_{p}}$

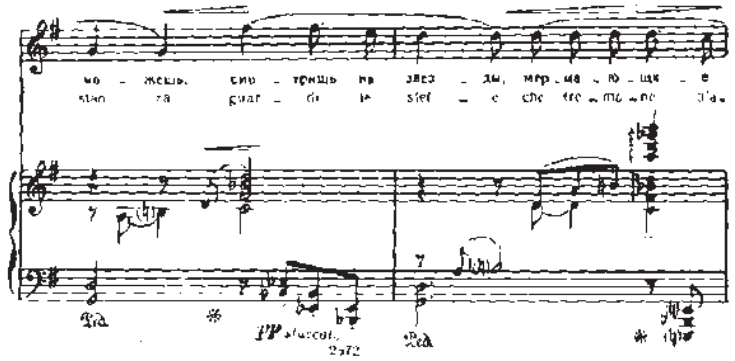


$n_{p}^{n}$

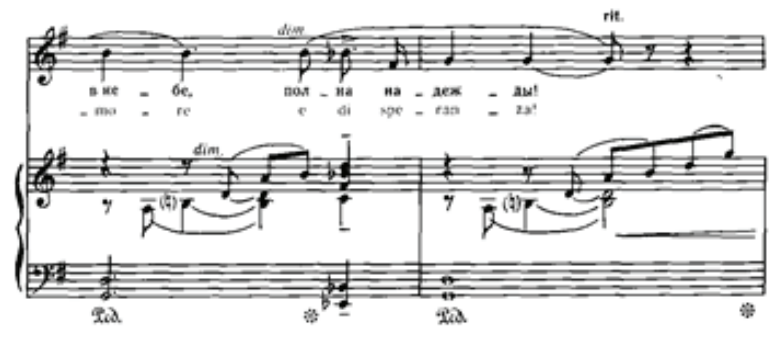

$\prod_{p}^{n_{0}}$

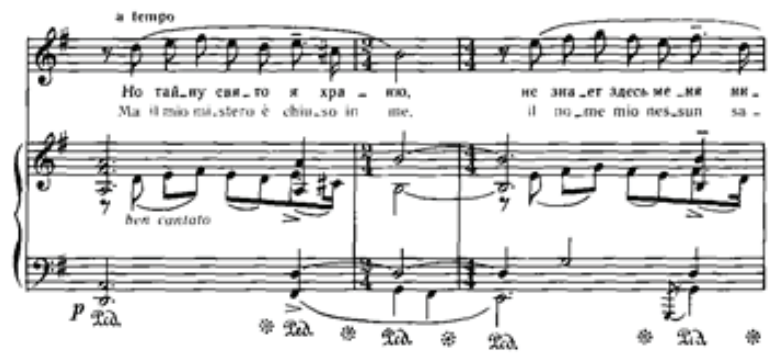

${ }_{i n}^{n}$
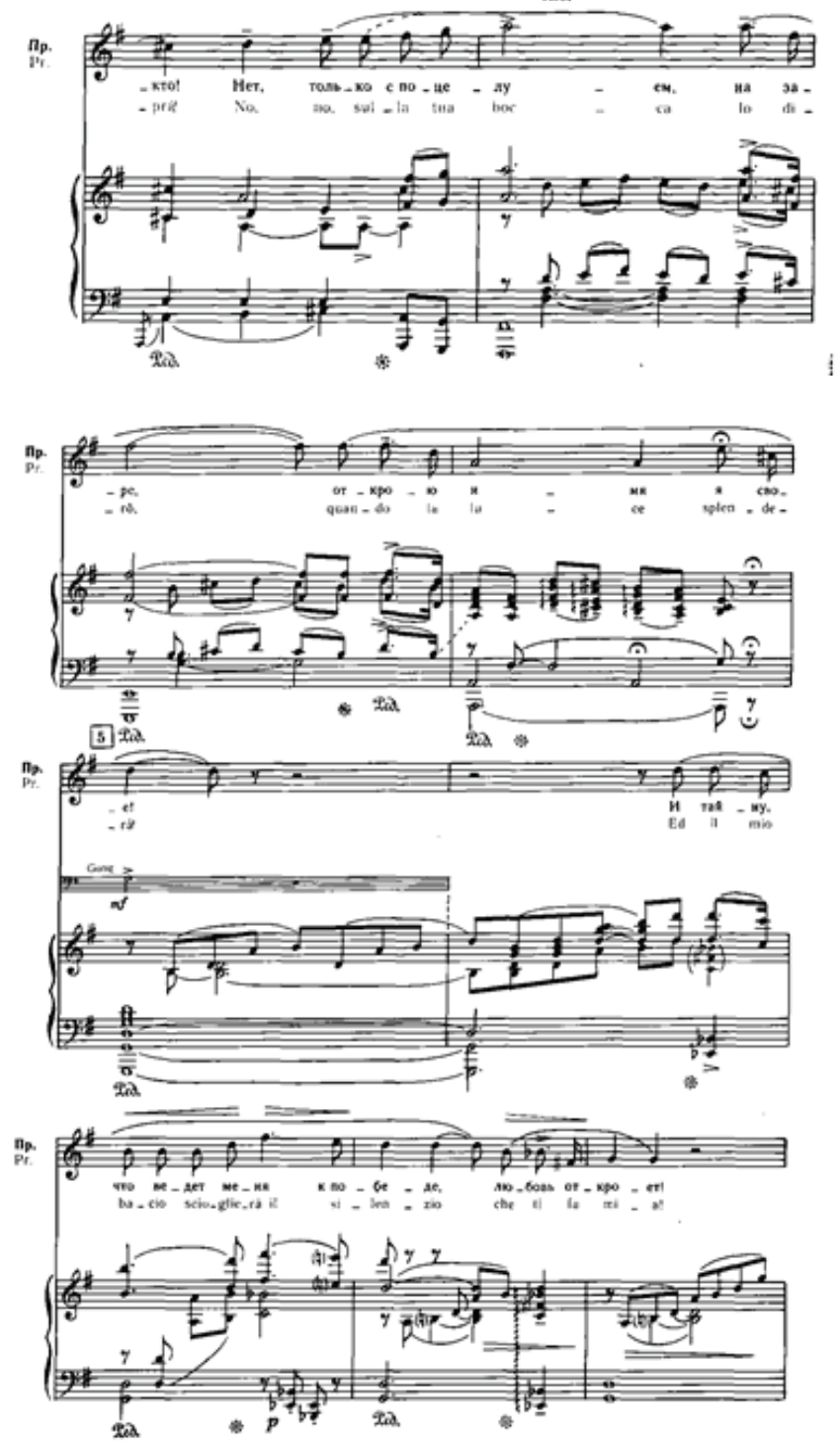

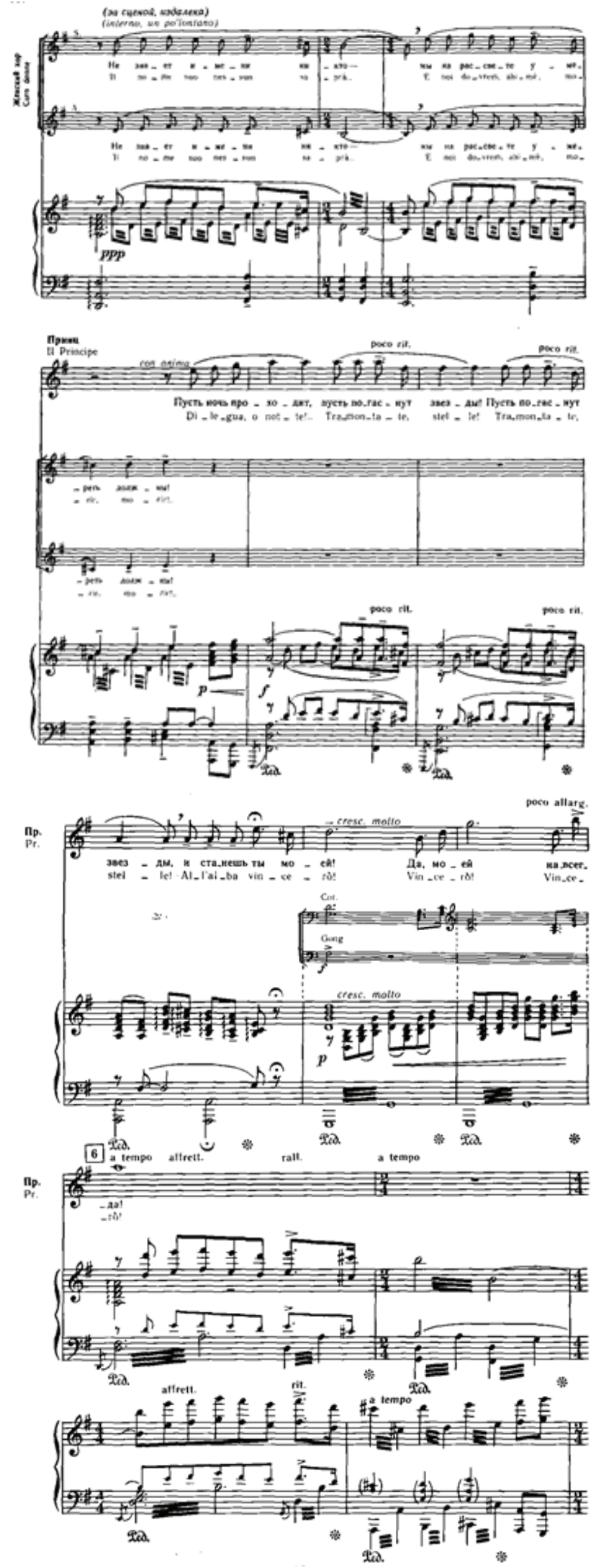
Example 3.

The end of the final number "Te Deum" (the act 1 of the Opera "Tosca").

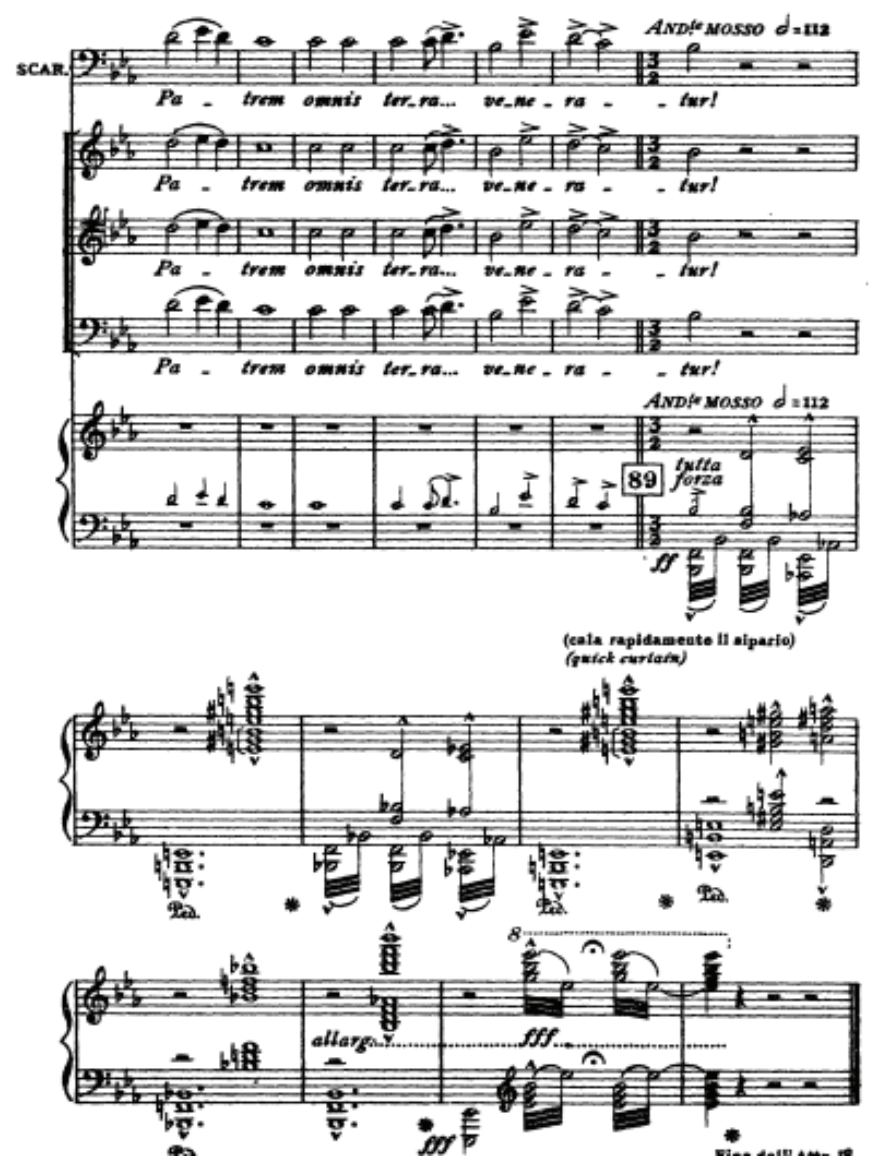

